
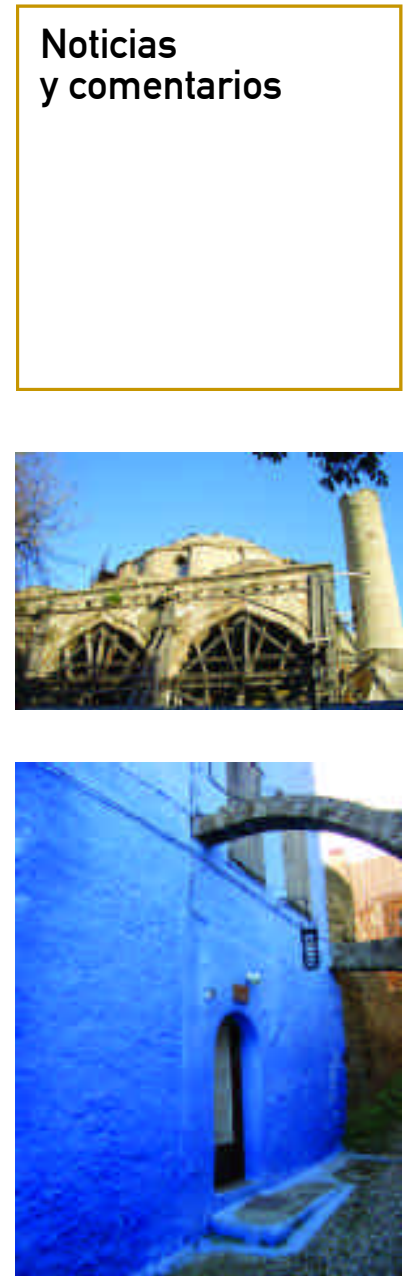

${ }^{1}$ El programa Euromed Heritage se desarrolla a partir del tratado de Barcelona de 1995. Con este tratado, la Unión Europea instaura con los paises sur mediterráneo un nuevo proceso que, de acuerdo con los dictámenes comerciales acuerdo con los dictámenes comercias
neoliberales y los Planes de Ajuste neoliberales y los Planes de Ajuste
Estructural, tiene por objetivo instaurar en el Mediterráneo una Zona de Libre Comercio (ZLC) dentro del año 2010 a través de acuerdos bilaterales con los distintos gobiernos, algunos de los cuales son ya operativos. La llamada Declaración de Barcelona se compone de tres pilares (político, económico y socio cultural) que son los tres ejes principales alrededor de son los tres ejes principales alrededor de
los cuales se desarrolla en la actualidad la acción de la UE en el Mediterráneo. Del mismo tratado de Barcelona y relacionado con el tercer punto de actuación (social, cultural y humano) nacen los programas Euromed Heritage I y II, con la intención de promover un patrimonio cultural euromediterráneo común en la cuenca mediterránea, probablemente, más funcional a los intereses económicos y políticos en la región.

\title{
¿La construcción de una identidad cultural Euromediterránea?
}

Durante los días 17, 18 y 19 de marzo se celebró en la isla de Rodas (Grecia) el III taller de trabajo en el marco de actividades desarrolladas en el proyecto DELTA, denominado "Desarrollo de la identidad cultural mediterránea". DELTA (Desarrollo de Sistemas Culturales Territoriales) es uno de los proyectos financiados por la Comisión Europea dentro del programa EUROMED HERITAGE ${ }^{1}$ II. El objetivo explícito para el que ha sido creado este programa que se inició en 1997 es el de preservar y desarrollar el patrimonio cultural del área Euro-Mediterránea. En la segunda fase (2002-2005) del Euromed Heritage, en la que se integra el proyecto DELTA, el programa debe operar sobre el patrimonio cultural a través de tres ejes fundamentales: conocimiento, recursos humanos y puesta en valor.

A este III taller del proyecto Delta, asistimos representantes de los diferentes partners involucrados en el mismo: cuatro países de la Unión Europea (Francia, Grecia, Italia y España) y cinco paises del mediterráneo sur (Argelia, Autoridad Palestina, Israel, Malta y Marruecos). Además de las sesiones de trabajo, se realizaron dos visitas culturales, una por la ciudad de Rodas y otra al sitio arqueológico de Lindos.

En la sesión introductoria Identidad y cultura en la región mediterránea, se expusieron los ejes conceptuales del proyecto Delta relacionados con la identidad cultural Euromediterránea a través de la conferencia de Andrea Amato como presidente del IMED (Istituto per il Mediterraneo). Como participante desde el IAPH, en calidad de etnóloga, debía desempeñar la función de raporter de la segunda sesión de trabajo dedicada a la identidad y puesta en valor del patrimonio cultural. En esta sesión de trabajo los participantes debían responder a tres cuestiones: la primera acerca de la relación entre patrimonio cultural, identidades culturales y actividades de conservación y puesta en valor; la segunda cuestión se centraba en si se refleja en las actividades de conservación y puesta en valor lo que se planteaba como una polaridad: la identidad cultural y la diversidad; la tercera cuestión fue: ¿cómo podemos desarrollar en las comunidades un sentido de pertenencia al patrimonio cultural de su territorio si ellos no se sienten representados en él? y ¿cómo pueden las políticas culturales dirigir la construcción de una identidad cultural compartida a nivel territorial?

A estas cuestiones, directamente relacionadas con el modelo conceptual expuesto por el presidente del IMED, quien plantearía sus reservas acerca de la existencia de una identidad cultural mediterránea y afirmaría la necesidad de crear una identidad cultural Euro-mediterránea, respondieron los diferentes participantes más o menos directamente.
La primera intervención fue la de T. Selwyn, profesor de Antropología de la Universidad Metropolitana de Londres, que trató sobre el patrimonio inmaterial a través del proyecto "Mediterranean voices" en ciudades históricas del mediterráneo (Marsella, Ancona, Jerusalén...). En este proyecto, en el que colaboran 13 países, se trabaja en la recuperación de historias de vida en torno a siete temas: personas, convivencia, trabajo, juegos, devociones, objetos y espacios. Es importante destacar que no centran su atención en el patrimonio monumental sino en las voces más silenciadas y marginadas de dichas ciudades. Realizó una reflexión crítica acerca de las actividades europeas de conservación y puesta en valor del patrimonio de dichas ciudades y de cómo estas actividades están colaborando, por un lado, a la destrucción de una de las más importantes peculiaridades de la ciudad mediterránea: el histórico contacto entre diferentes pueblos e identidades culturales, y al mismo tiempo, están apoyando la construcción de nuevos barrios sin sus vecinos tradicionales, y colaborando a la especulación urbanística y a la creación de centros históricos convertidos en auténticos parques temáticos vacíos de sus agentes culturales más vivos y heterogéneos: sus habitantes y sus relaciones.

En segundo lugar, el director del Proyecto de Restauración de la ciudad Medieval de Rodas nos habló acerca de las diferentes influencias que se pueden apreciar en la vieja ciudad de Rodas y mostró a través de las obras pictóricas, grabados, etc., como la identidad de los habitantes de Rodas es el resultado de un pasado histórico multiétnico.

Finalmente, D. Theuma, de la Universidad de Malta, exploró con su exposición el patrimonio cultural de Malta y nos presentó la identidad cultural de los malteses como consecuencia de un largo proceso histórico, una superposición de diferentes pueblos y culturas y un fuerte sentido de supervivencia. Describió la identidad de los malteses a través de la visión que tienen de ellos mismos y de la imagen que perciben quienes los visitan. En este punto, afirmó que los malteses se autoperciben más como europeos que como mediterráneos (entendiéndose por "mediterráneos", norte-africanos) y empleando el pasado templario de los Cruzados de San Juan como marcador identitario fundamental de la isla, frente a otros rasgos culturales que los asimilaría más al mundo árabe. La exposición de Nadia resultó ser la aplicación concreta de la construcción conceptual que sobre las identidades culturales y los "sistemas culturales territoriales" nos había expuesto el presidente del IMED. Si debiésemos responder a las preguntas arriba planteadas, acerca de qué patrimonio poner 
en valor con nuestras políticas culturales, resultaba claro que atendiendo exclusivamente a la percepción de los habitantes encuestados en la actualidad maltesa (perspectiva emic), se debería reforzar la visión de los malteses como partes de una "Europa moderna" y no como herederos de un pasado "norteafricano".

Estos planteamientos se reflejaban también en nuestras visitas guiadas por la ciudad medieval de Rodas y por el sitio arqueológico griego restaurado por las fuerzas italianas de ocupación en el período fascista, huellas que se hacian notar en el neoclasicismo de algunos edificios de la isla y en el modo en que se había intervenido en el yacimiento arqueológico de Lindos. La parte islámica de la herencia cultural de la ciudad medieval que no vimos en la visita oficial (reflejadas en las fotos), además del franco deterioro de algunas mezquitas, frente a la reconstrucción prácticamente ex novo del castillo de los cruzados de San Juán en la que se celebró el taller, son también reflejo de qué elementos de la herencia cultural se están poniendo en valor en algunos países para la creación de una identidad cultural Euromediterránea, frente a la supuesta inexistencia de una identidad mediterránea.

La segunda y tercera sesión se dedicaron a exponer proyectos que sivieran de ejemplos para la conversión de las identidades culturales en productos mercantiles y se denominaban respectivamente "Identidades Culturales y producción cultural, imagen y comunicación" e "identidades culturales y marketing territorial". Por último la mesa redonda se centró en "la cooperación y los recursos culturales". Estas sesiones mostraban de forma más clara los objetivos implícitos de la creación de una identidad cultural Euro-mediterránea.

Nuestra aportación en el ámbito conceptual fue la de abogar por un concepto de identidad cultural dialéctico y no esencialista, resultante de una experiencia histórica colectiva en todos los ámbitos, que genera un conjunto de valores y actitudes compartidas y que se refleja en las culturas de los diferentes pueblos mediterráneos, aunque estos sean más o menos conscientes de ello. Por ello, la identidad cultural no responde al voluntarismo o a los intereses momentáneos de un grupo. Las identidades culturales euro-mediterráneas probablemente no existan y sea necesario construirlas, pero las identidades culturales mediterráneas están marcadas por un pasado multicultural y por una diversidad que es su principal valor, producto de miles de años de historia de contactos y relaciones. Creemos que Andalucía y su patrimonio cultural es un ejemplo claro de la convivencia de diferentes culturas y que este discurrir dialéctico de su historia es una de las razones de su existencia como pueblo.

Gema Carrera Diaz

Antropóloga

Centro de Documentación del IAPH

Cuadernos del IAPH disponibles desde la librería virtual y la institucional

$>$ Cuadernos Técnicos

1. Procedimientos de análisis documental automático: estudio de caso, 1996

3. Principios del lenguaje epistemográfico: la representación del conocimiento sobre patrimonio histórico andaluz, 1998

4. Prevención de riegos laborales en la investigación e intervención en Patrimonio Histórico, 1999

5. Conservación de colecciones de fotografía, 2001

6. Arqueos: Sistema de Información del Patrimonio Arqueológico de Andalucia, 2002

7. Antropología y patrimonio: investigación, documentación e intervención, 2003

8. Metodología de diagnóstico y evaluación de tratamiento para la conservación de los edificios históricos, 2003

$>$ Cuadernos

VII. Difusión del Patrimonio Histórico, 1996

VIII. Historia del Arte y Bienes Culturales, 1998

IX. Indicadores para la evaluación del estado de conservación de Ciudades Históricas, 1999

X. Patrimonio Etnológico. Nuevas perspectivas de estudio, 1999

XI. La arquitectura Moderna en Andalucía: un patrimonio por documentar y conservar. La experiencia DOCOMOMO, 1999

XII. Preservación de la Arquitectura Industrial en Iberoamérica y España, 2001

XIII. Arte y politica en España: 1898-1939, 2002

XIV. Repertorio de textos internacionales de patrimonio cultural, 2003

XV. Territorio y Patrimonio: Ios Paisajes Andaluces, 2003

Tesauro de Patrimonio Histórico Andaluz, 1998

Librería institucional

C/ José Luis Luque, 2 (Plaza de la Encarnación). 41003 Sevilla

Tel.: 955040418 Fax: 955037339

Correo-e.: libreria.ccul@juntadeandalucia.es

Librería virtual

Web: www.juntadeandalucia.es/cultura/libreriavirtual 